\title{
Strategi Komunikasi Pemasaran Candi Plaosan dalam Meningkatkan Jumlah Pengunjung Tahun 2018
}

\author{
Rizki Maulana Hasan ${ }^{1}$ \\ ${ }^{1}$ Magazine of Communication Ahmad Dahlan, Universitas Ahmad Dahlan, Indonesia
}

\begin{abstract}
Article Info
ABSTRACT

Article history:

Received March 12, 2018

Accepted April 16, 2018

\section{Keywords:}

Jumlah Pengunjung

Candi Plaosan

Promosi

Pemasaran

Strategi Komunikasi

Penurunan tingkat kunjungan pada Candi Plaoasan terlihat dari data statistik pengunjung tahun 2014-2018 yang menunjukkan bahwa pada tahun 2016 jumlah pengunjung Candi Plaosan sempat mengalami penurunan. Kurangnya pihak UPT Candi Plaosan promosi sehingga berkurangnya minat pengunjung, candi plaosan cukup kurang perhatian dari pemerintah, candi plaosan tidak memiliki ruang-ruang pemujaan seperti candi lain, dan beberapa patung yang ada disekitar candi sudah tak lagi utuh, beberapa di antaranya hilang kepalanya. Jenis penelitian yang digunakan adalah deskriptif kualitatif. Datadata yang diperoleh dari membandingkan data hasil pengamatan dengan hasil wawancara, membandingkan hasil wawancara dengan isi suatu dokumen yang berkaitan, membandingkan hasil wawancara dengan isi dokumen yang sudah di peroleh peneliti, baik itu dari Candi Plaosan dan beberapa data dan sumber lain yang mendukung. Hasil penelitian ini menunjukan bahwa promosi yang dilakukan pihak UPT Candi Plaosan belum efektif, melihat dari data pengunjung yang mengalami fluktuatif. Masih sangat perlu pengelolaan yang lebih baik lagi untuk meningkatkan jumlah pengunjung.
\end{abstract}

This is an open access article under the CC BY-SA license.

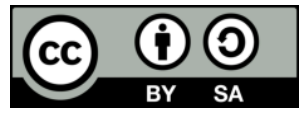

\section{Corresponding Author:}

Rizki Maulana Hasan,

Magazine of Communication Ahmad Dahlan, Universitas Ahmad Dahlan, Indonesia,

Email: rizki@comm.uad.ac.id

\section{PENDAHULUAN}

Candi merupakan istilah yang merujuk pada sebuah bangunan keagamaan peninggalan purbakala yang berasal dari peradaban Hindu-Budha. Pada zamannya bangunan ini digunakan sebagai tempat peribadahan atau pemujaan terhadap dewa-dewi Budha. Candi merupakan bangunan replika dari tempat tinggal dewa yang sebenarnya, yaitu Gunung Mahameru. Karena itu, seni arsitekturnya dihias dengan berbagai macam ukiran dan pahatan berupa pola hias yang yang disesuaikan dengan alam Gunung Mahameru yang dimana setiap relief dan arsitektur tak lepas dari unsur spiritualitas. Indonesia memiliki sekitar 131 candi yang masing-masing tersebar di beberapa daerah seperti, Jawa Barat, Jawa Tengah, Daerah Istimewa Yogyakarta(DIY), Jawa Timur, Bali, Sumatra dan Kalimantan. Candi di Indonesia memiliki berbagai macam corak yang beragam antara lain, Hindu, Budha dan Hindu Budha.

Daerah jawa Tengah khususnya Kabupaten Klaten terdapat Candi Plaosan yang bercorak Budha. Percandian Plaosan merupakan salah satu komplek percandian yang terletak di Dukuh Plaosan, Desa Bugisan, Kecamatan Prambanan, Kabupaten Klaten, Provinsi Jawa Tengah, Indonesia. Candi ini terletak kira-kira 1 kilometer ke arah timur laut dari Candi Prambanan. Secara astronomis percandian Plaosan terletak pada titik kordinat $7^{\circ} 44^{\prime} 32$ Lintang Selatan dan 110 30' 11,07 Bujur Timur. Candi Plaosan ini sangat unik dan menarik karena terbagi dari dua bagian yaitu Candi Plaosan Lor dan Candi Plaosan Kidul sehingga sering disebut candi kembar. Candi Plaosan merupakan sebuah komplek percandian yang sangat luas. Candi Plaosan merupakan candi bercorak Budha yang dibangun pada abad ke-9 M, saat pada masa kerajaan Mataram Kuno.

Komplek percandian ini dibangun oleh raja dan permaisurinya yang bernama Rakai Pikatan dengan 
Pramudya Wardhani. Menurut salah satu sumber, Rakai Pikatan adalah seorang raja dari Wangsa Sanjaya pada masa kerajaan Mataram Kuno yang beragama Hindu. Sedangkan Pramudya Wardhani adalah keturanan dari Wangsa Sailendra yang merupakan keturunan kerajaan beragama Budha. Pada data sejarah yang tertulis menurut salah satu sumber, bahwa Candi Plaosan merupakan bukti cinta Rakai Pikatan kepada Pramudya Wardhani. Sebab pada waktu itu, telah diketahui bahwa pernikahan antara Rakai Pikatan dengan Pramudya Wardhani tidak disetujui oleh masing-masing keluarga besar (wangsa). Keduanya memang sama-sama berasal dari dua kerajaan yang pernah berjaya di Jawa, akan tetapi berbeda prinsip, budaya, dan agama. Meskipun adanya pertentangan keduanya memutuskan untuk menikah. Maka dibangunlah Candi Plaosan sebagai bentuk simbol keabadian cinta mereka. Konon, Candi Plaosan dibuat sendiri oleh Rakai Pikatan dengan permaisurinya, Pramudya Wardhani.

Candi Plaosan terletak di letak Candi Plaosan Lor berada di Dukuh Plaosan, Desa Bugisan, Kecamatan Prambanan, Kabupaten Klaten, Provinsi Jawa Tengah. Candi ini berada 1,5 kilometer di timur Candi Sewu tidak jauh dari Candi Prambanan sekitar 3 kilometer di timur laut dan 1,5 kilometer ke arah utara jalan raya Yogyakarta-Solo. Promosi pariwisata pada dinas pariwisata kebudayaan pemuda dan olahraga kabupaten Klaten dilakukan melalui pembuatan anjungan dalam ekspo-ekspo pembangunan dan kepariwisataan. Dinas pariwisata Kabupaten Klaten menyediakan dan membagikan leaflet dan booklet pada anjungan mereka. Kelebihan promosi melalui ekspo ini adalah biayanya relatif lebih murah, namum kelemahannya adalah hanya dapat menjangkau publik yang mengunjungi ekspo dan biasanya pengunjungnya adalah masyarakat lokal. Promosi yang dilakukan Candi Plaosan kurang gencar sehingga mengakibatkan menurunnya minat pengunjung, akibat dari kurangnya promosi beberapa obyek wisata di Klaten termasuk Candi Plaosan kurang dikenal oleh masyarakat, padahal obyek wisata di Klaten banyak mengandung unsur-unsur sejarah edukasi. Penurunan tingkat kunjungan pada Candi Plaoasan terlihat dari data statistik pengunjung tahun 2014-2018 yang menunjukkan bahwa pada tahun 2016 jumlah pengunjung Candi Plaosan sempat mengalami penurunan.

\section{METODE}

\subsection{Theoritical framework}

Strategi. Strategi adalah bagaimana pertahanan hidup dalam dunia kompetitif, bagaimana membuat persepsi baik di benak konsumen, menjadi berbeda, mengenali kekuatan dan kelemahan pesaing, menjadi spesialisasi, menguasai suatu kata yang sederhana di kepala, kepemimpinan yang memberi arah dan memahami realitas pasar dengan jadi yang pertama daripada menjadi yang lebih baik (Hasan, 2010). Selain itu juga definisi strategi dijelaskan Tjiptono (2007), dimana konsep strategi dapat didefinisikan berdasarkan dua persfektif yaitu: Perspektif apa yang diinginkan organisasi lakukan, strategi dapat di definisikan sebagai program untuk menentukan dan mencapai tujuan organisasi dan mengimplementasikan misinya. Perspektif apa yang organisasi akhirnya lakukan, strategi didefinisikan sebagai pola tanggapan atau respon organisasi terhadap lingkungan sepanjang waktu (Tjiptono, 2002).

Komunikasi Pemasaran. Komunikasi pemasaran disebut juga bauran promosi yang merupakan alat efektif untuk berkomunikasi dengan pelanggan (baik konsumen atau perantara). Menurut Tjiptono (2002) komunikasi pemasaran adalah aktifitas pemasaran yang berusaha menyebarkan informasi mempengaruhi atau membujuk, dan atau mengingatkan pasar sasaran atas perusahaan dan produknya agar bersedia menerima,membeli, dan loyal pada produk yang ditawarkan perusahaan yang bersangkutan. Sedangkan menurut komunikasi pemasaran menurut Kotler dan Keller (2009), menyatakan bahwa komunikasi pemasaran yaitu dimana perusahaan berusaha menginformasikan, membujuk, dan mengingatkan konsumen secara langsung maupun tidak langsung tentang merk yang dijual. Adapun beberapa bentuk komunikasi pemasaran akan peneliti jelaskan pada bagian selanjutnya, di antara lain sebagai berikut :

Advertising. Periklanan (advertising) adalah semua bentuk penyajian dan promosi non personal atas, ide barang atau jasa yang dilakukan oleh perusahaan tertentu. Karena banyaknya bentuk periklanan, sangat sulit untuk membuang generalisasi yang merangkum semuanya. Namun, kualitas khusus berikut sepatutnya diperhatikan (Morisson et al., 2011).

Event Organizer. Ada dua fokus utama sebagai tolak ukur keberhasilan suatu event. Tolak ukur yang pertama adalah kesuksesan dalam kemasan dan berlangsungnya acara, sedangkan, tolak ukur yang kedua adalah profit oleh sebab itu dua hal yang di atas event dibagi menjadi dua jenis. Event murni yaitu event yang segala sesuatu ditanggung dan diselenggarakan oleh event organizer dan pelaksanaan event dapat menjadi keuntungan pihak event organizer (Beatrix, 2006).

Word of Mouth. Kebanyakan proses komunikasi adalah melalui dari mulut ke mulut (Sutisna, 2003), menemukan bahwa komunikasi melalui WOM adalah paling penting dalam mempengaruhi barang-barang konsumsi, barang-barang pengguna jasa. Seperti juga yang dijelaskan oleh Shimp (2003), ada dua sumber informasi personal dan impersonal. Sumber-sumber impersonal meliputi informasi yang diterima oleh televisi, majalah, dan internet, serta berbagai sumber media massa lainnya. Sedangkan sumber-sumber personal meliputi pengaruh komunikasi lisan dari teman-teman, para kenalan, serta relasi bisnis dan kasus pengambilan 
keputusan oprasional.

Pemasaran Via Internet. Pemasaran internet (internet marketing), juga disebut sebagai pemasaran, web marketing, online marketing adalah pemasaran produk atau jasa melalui internet. Pemasaran internet juga mengacu pada penempatan media bersama sebagai tahapan dari siklus keterlibatan pelanggan melalui pemasaran mesin pencari. Dengan menghitung empat jenis interaksi dengan situs web perusahaan disamping hits pada iklan disajikan dari jaringan periklanan, ditemukan potensi untuk menemukan data rata-rata 2500 kali respon dari pengguna perbulan (Hermawan, 2012).

Pariwisata. Pariwisata sebagai gabungan dari gejala dan hubungan yang muncul dari interaksi wisatawan yang datang, bisnis, pemerintah dan masyarakatnya sebagai tuan rumah dalam proses menarik dan melayani para pariwisat (Kusmayadi, 2000). Dari sudut pandang ekonomi, sektor pariwisata memiliki peluang untuk perolehan devisa Negara. Maju dan berkembangnya pariwisata dapat mengembangkan daerah miskin menjadi lokasi industri baru. Sektor pariwisata merupakan alternatif dengan prosfek yang menjanjikan untuk menanggulangi kemiskinan. Pariwisata adalah faktor penting dalam membangun ekonomi Negara, karena mendorong perkembangan beberapa sektor perekonomian nasional (Yoeti, 2008).

\subsection{Proposed Method}

Jenis penelitian yang digunakan peneliti adalah kualitatif dengan metode deskriftif. Menurut Bogdan \& Tailor dalam (Moleong, 2014), mendefinisikan "metodologi kualitatif sebagai prosedur penelitian yang menghasilkan data deskriftif berupa kata-kata tertulis atau lisan dari orang-orang dan perilaku yang dapat di amati”. Penelitian ini akan dilakukan pada obyek Candi Plaosan yang berlokasi di Jl. Candi Plaosan, Plaosan Lor, Bugisan, Kec. Prambanan, Kabupaten Klaten, Jawa Tengah. Peneliti mengambil tempat penelitian disini karena Candi ini sarana pendidikan prasejarah dan pengetahuan bagi seluruh dunia dan menjadi wisata di Indonesia. Penelitian ini akan dilakukan pada bulan April-Agustus 2019. Metode pengumpulan data dengan interview adalah salah satu metode pengumpulan data yang dilakukan dengan cara pertanyaan langsung dengan informan dan dikerjakan secara sistematis berlandaskan pada tujuan penyelidikan. Wawancara yang digunakan dalam penelitian ini yaitu in depth interview. Namun demikian, peneliti boleh melakukan wawancaran untuk penelitian kualitatif secara berstruktur. Pedoman wawancara atau interview guide dengan tujuan agar wawancara tidak menyimpang dari permasalahan . Pertanyaan penelitian ditujukan untuk: (1) Kepala UPT, marketing, dan karyawan Balai Pelestarian Cagar Budaya Jawa Tengah, yang bertujuan untuk mendapatkan informasi mengenai bagaimana Strategi Komunikasi Pemasaran Candi Plaosan Dalam meningkatkan Jumlah Pengunjung Tahun 2018. (2) Wisatawan, yang bertujuan untuk mendapatkan informasi darimana mereka mengetahui tentang adanya Candi Plaosan serta bagaimana pendapat mereka setelah mengunjungi Candi Plaosan. (3) Pemerintah Desa Bugisan, Kecamatan Prambanan, Kabupaten Klaten, Provinsi Jawa Tengah, Indonesia. Selama melakukan wawancara, peneliti boleh menanyakan hal-hal yang berkenaan: (1) Pengalaman dan perbuatan informan, yaitu apa yang telah dikerjakan atau yang lazim dikerjakan. (2) Pendapat, pandangan, tanggapan, tafsiran, atau pikiran tentang suatu yang berkenan dengan penelitian yang sedang dilakukan. (3) Perasaan, respons emosional, yakni apakah ia merasa cemas, takut, senang, gembira, curiga, jengkel, dan sebagainya tentang sesuatu. (4) Pengetahuan, fakta-fakta apa yang diketahui tentang sesuatu yang diteliti. (5) Pengindraan yakni apa yang dilihat, didengarkan, diraba, dikecap, atau diciumnya diuraikan secara deskritif. (6) Latar belakang pendidikan dan hal-hal yang mencakup perkerjaan, daerah asal, tempat tinggal, keluarga dan hal lainnya yang berkenaan dengan penelitian yang dilakukan (Tohirin, 2012)

Dokumentasi terdiri dari dua macam yaitu, dokumentasi pribadi dan dokumentasi resmi. Dokumen pribadi, seperti: buku harian yang dibuat oleh subyek yang diteliti, surat pribadi yang dibuat dan diterima oleh subyek yang diteliti dan otobiografi, yaitu riwayat hidup yang dibuat sendiri oleh subyek peneliti atau informan peneliti. Dokumen resmi, seperti surat keputusan SK dan surat-surat resmi lainnya. Data ini dikumpulkan dengan cara memfotokopi atau difoto menggunakan alat foto atau kamera tangan (Tohirin, 2012). Dalam penelitian ini dilakukan dokumentasi terhadap obyek yang diteliti, yaitu dokumen atau arsip-arsip yang berhubungan dengan Candi Plaosan dan untuk memperkuat dan mendukung hasil penelitian yang telah diperoleh. Dalam penelitian ini, dokumentasi memang penting digunakan karena dapat mendukung dan menambah bukti dari sumber-sumber lain. Referensi yang digunakan dalam penelitian ini dapat berupa foto, bentuk-bentuk alat promosi, dan data-data tertulis yang berhubungan dengan kegiatan promosi.

\section{HASIL DAN PEMBAHASAN}

Hasil peneltian yang dilakukan "Strategi Komunikasi Pemasaran Candi Plaoasan Dalam meningkatkan Jumlah Pengunjung Tahun 2018". Penelitian ini melibatkan tiga informan yang merupakan Kepala UPT, wisatawan, pemerintah Desa Bugisan. Lokasi penelitian ini dilakukan di Dukuh Plaosan, Desa Bugisan, Kecamatan prambanan, Kabupaten Klaten, Provinsi Jawa Tengah, Indonesia. Penelitian ini dilakukan dengan memberikan pertanyaan-pertanyaan dari pedoman wawancara namun tidak berstruktur sehingga hasil wawancara dapat berkembang. Peneliti menggunakan metode kualitatif, studi deskriptif kualitatif untuk 
melihat strategi komunikasi pemasaran objek wisata candi plasoan . penelitian kualitatif merupakan prosedur penelitian yang menghasilkan data-data deskriptif berupa kata-kata tertulis atau lisan didasari oleh orang atau perilaku yang diamati.

Periklanan yang dilakukan oleh kepala UPT, marketing dan karyawan Candi Plaosan dengan melakukan strategi periklanan melalui beberapa cara. Semua itu dilakukan semata-mata untuk menarik minat berkunjung masyarakat ke Candi Plaosan. Kepala UPT, marketing dan karyawan Candi Plaosan melakukan Periklanan kepada pengunjung untuk menarik minat kunjungan ke Candi Plaosan, yakni: Strategi kami melalui pendekatan dengan cara mendatangi sekolah-sekolah, pedesaan dan komunitas-komunitas. Media yang kami gunakan diantaranya melalui pembagian leaflet, majalah, poster dan penanyangan film pendek tentang sejarah Candi Plaosan yang pemutarannya menggunakan media BIOLING (BIOSKOP KELILING) yang tujuannya untuk memperolah feedback yang nantinya berpengaruh ke peningkatan jumlah pengunjung Candi Plaosan. Program BIOLING (BIOSKOP KELILING) biasanya di adakan 1 tahun sekali dan berlokasi di 10 titik tertentu.

Kegiatan BIOLING (bioskop keliling) diisi dengan serangkaian acara yakni pemutaran film cagar budaya, ceramah cagar budaya, dan kuis BIOLING cagar budaya. Sasaran dari kegiatan tersebut adalah warga pedesaan, komunitas-komunitas, dan sekolah-sekolah. Bus BIOLING berputar di 10 titik Candi Plaosan termasuk pedesaan, komunitas dan sekolahaan. Dengan di adakannya BIOLING (Bioskop Keliling) di harapkan meneguhkan keeksistensian Candi Plaosan. Keeksistensian yang tidak di ukur secara fisik yang hanya mengedepankan kelestarian bangunan saja, namun juga menjaga agar lestari dalam ingatan generasi muda.

\section{KESIMPULAN}

Berdasarkan hasil penelitian dan pembahasan yang telah diuraikan sebelumnya, strategi komunikasi pemasaran dalam meningkatkan jumlah pengunjung. Berdasarkan penelitian yang dilakukan oleh peneliti, peneliti memiliki beberapa saran dan masukan sebagai bahasan pertimbangan untuk UPT Candi Plaosan dalam meningkatkan pengunjung.

\section{REFERENSI}

Beatrix, S. (2006). I Love Organize. Panduan Praktis Mengelola Event. Jakarta: Gramedia Pustaka Utama

Hasan, A. (2010). Marketing Bank Syariah. Jakarta : Ghalia Indonesia.

Hermawan, A. (2012). Komunikasi pemasaran.

Kotler dan Keller. (2009). Manajemen pemasaran. Jilid I. Edisi ke, 13.

Kusmayadi, S.E. (2000). Metode penelitian dalam bidang pariwisata. Jakarta: grameda pustaka utama.

Moleong, J. L.(2014). Qualitative Research Methodology. Bandung: PT. Youth Rosdakarya.

Morrison, M. A., Haley, E., Sheehan, K. B., \& Taylor, R. E. (2011). Using qualitative research in advertising: Strategies, techniques, and applications. Sage Publications.

Shimp, T. A. (2003). Advertising, Promotion and Supplemental Aspects of Integrated Marketing Communications. Mason, Ohio: Thomson Southwestern.

Sutisna. (2003). Perilaku Konsumen dan Komunikasi Pemasaran, Cetakan Ketiga. Bandung:

PT. Remaja Rosdakarya.

Tjiptono, F. (2007). Strategi Pemasaran, edisi kedua. Yogyakarta: Andi.

Tjiptono, F. (2002). Strategi bisnis. Edisi Pertama. Yogyakarta: Penerbit Andi.

Tohirin, D. (2012). Metode Penelitian Kualitatif dalam Pendidikan dan Bimbingan Konseling. Jakarta: Raja Grafindo Persada.

Yoeti, O.A. (2008). Ekonomi Pariwisata: Introduksi, Informasi, dan Implementasi. Jakarta: Kompas. 